\title{
4
}

\section{Practice Makes Perfect? University Students' Response to a First-Year Transition Course}

\author{
Catherine Browning \\ Concordia University \\ Suzanne Le-May Sheffield \\ Dalhousie University
}

This paper shares new insights on the first-year university student transition experience. Our research focuses on students' practice of academic skills developed in a 'Foundations for Learning' course, from their own perspective, after they completed the course. Once they had an opportunity to practice what they learned in subsequent courses we investigated how such practice impacts students' attitudes toward learning and their university experience.

\section{Introduction}

$\mathrm{O}$ ne of the challenges faced by transition course educator-advocates like ourselves, derives from a misperception that preparatory courses are remedial initiatives. John Gardner (2001) says "that only the fittest students survive and flourish, and the weakest fall by the wayside" as "academic Darwinism" (p. 5). He writes that, "in spite of more contemporary concerns about student attrition, this attitude persists among many college faculty, administrators, and trustees" (p. 5).

We suggest that the struggles of first-time university students say more about their need for formal assistance through a transition course like Foundations for Learning, than it does about not belong- ing or not having the 'right stuff.' In response to our survey question, "What should universities know about first-year students?" participants suggested that universities and faculty should not assume that university-appropriate skills are taught in high school:

The expectations are so much greater in terms of paper content and workload [than] in high school.

I realized [that] university is a really independent learning process and I found so many things I don't know. 
Foundations for Learning gives students the opportunity to learn the skills they will need for their entire academic career, without taking for granted that you know what many students would think is common knowledge, like using the library or how to reference a book.

In their study of three British Columbia post-secondary institutions, Andres, Andruske, and Hawkey (1996) report that without access to or knowledge of resources and success strategies, first-year students feel "helpless and powerless" and "voiceless" (p. 124). Our respondents expressed similar feelings:

The workload and expectations are such a shock. I was wondering how to learn things by ourselves. University is a scary place, especially in your first year. It's just as hard, if not harder to go to university at 30 .

Typically, skills' course assessments report higher retention and completion rates, positive student attitudes toward university, higher grades as they progress through university than they otherwise might have received, and increased social interaction with faculty and other students, often regardless of students' age, social class, gender or ethnic/racial/cultural background (Sherman, 1991; Hyers \& Nesest, 1998; Starke, Harth, \& Sirianni, 2001; Schnell, Louis, \& Doetkott, 2003).

Students themselves are cognizant of the value of transition courses. One York University study (Grayson, 1994) found that 40-50\% of first-year students did not feel that they had been academically or emotionally prepared for university, and $60-75 \%$ felt that they were not prepared in terms of work habit and study skills. When asked if they thought a firstyear preparatory credit course would be a good use of their time, $40-50 \%$ of York's student respondents agreed that yes, it "would be a good, or a very good, use of time." Grayson suggests that:

Answers to this question confirm that firstyear students recognize that they have difficulties not currently covered by the formal curriculum and that they need help in dealing with such matters.... While the offering of such a course is unlikely to be a panacea, if offered properly, it could be a step in the right direction of dealing with some of the first year problems. (p. 21-22)

Several students responding to our survey after completing Foundations for Learning concurred with the sentiments expressed by students in Grayson's study:

Foundations for Learning should be a mandatory course!

As part of the writing requirement of the BA/BSc programs, the fundamentals taught by Foundations for Learning should be a core part of the...curriculum.

Undoubtedly, transition courses have been of value to the institution, faculty, and students. Our research project, Practice makes perfect?, expresses our interest in first-year university students and draws on our experiences teaching a first-year transition course, Foundations for Learning. However, unlike previous studies, we wanted to know: 1) whether students practiced learned skills and techniques after they completed the course; 2) what factors influenced their decision to apply what they were taught in future courses; and 3) what benefits accrued to students who chose to practice taught skills.

\section{The Course: Foundations for Learning}

Foundations for Learning was a 3-credit hour or "half-course" offered at Dalhousie University from Fall 2000 to Winter 2007. In 2006-2007, the Faculty of Arts and Sciences (FASS) offered three sections per semester and the Faculty of Science offered one section per semester. Participants were primarily first-year students who had earned 30 credit hours or less. Students with more than 30 credit hours could register with professor permission and some students 
on academic probation could be required to attend. Dalhousie University's 2006-2007 Undergraduate Calendar describes Foundations for Learning as follows:

This class, open to all first-year students at the University, introduces participants to university culture, and helps them to enhance academic performance. Classroom experiences build a practical understanding of the learning process at the university level, enabling students to develop strategies to be more efficient learners.

With these goals in mind, our course modules included, but were not limited to time management, studying, academic referencing, critical reading and analysis, essay research and planning, group presentation skills, research methods and ethics, intellectual curiosity, and personal challenges. Such topics generally accord with transition course designs at other Canadian universities and those addressed in university student success guides.

Statistics from 2004-2007 indicate that Foundations for Learning responded to first-year students' interest in developing their academic competence and confidence. In the 19 sections offered by the Faculty of Arts and Social Sciences (FASS), 545 students registered, exceeding the 540 ceiling. In the five sections offered by the Faculty of Science during that same time period, 116 students registered for 120 spaces. The fact that 661 students registered for 660 spaces in 24 sections over three years suggests that Foundations for Learning was economically profitable, developed a popular reputation, and was perceived as academically useful. We wondered, however, about its long-term impact on students' academic lives.

\section{Research Method}

A questionnaire was distributed via Web-CT to the university email addresses of 196 FASS and Science students in Foundations for Learning who had attended sections in the Fall of 2004, and the Winter and Summer of 2005. With the approval of Dalhousie Social Sciences and Humanities Human Research Ethics Board, 155 FASS and Science students in the Fall 2005 sections were later added, bringing the total to 351. In the end, no science students responded to the questionnaire. This could relate to the timing of our appeals, approaching and during mid-term exams, and/or science students' double burden of course and lab commitments.

Confronted by a generally slow response to our questionnaire, we sent three requests and three reminders to Dalhousie email addresses. Speculating that students might not be reading their university mail, we re-sent the questionnaire twice to their personal email addresses. Our decision to make a final third attempt involving three mail-outs and no reminders in March and April, 2006, derived from the unanticipated problem that some students had trouble accessing the questionnaire on WebCT. Ultimately, our response rate was $10 \%$. Twenty males and 15 females completed the questionnaire that was sent several times and ways to 351 students. Thirtytwo of the 35 were 28 years of age or younger. Thirtythree of the 35 were full-time students, and 29 spoke English as a first language.

We speculate that students' participation may have been influenced by the timing of the questionnaire before and during mid-term exams, or students' lack of interest in our research, or the absence of financial or grade incentives (Dommeyer, Baum, Hanna, \& Chapmen, 2004). The length of the questionnaire or technical ability may have discouraged others. It is also possible that in its lack of personal contact, the web-based format may have made our appeals easy to ignore (Cook, Heath, \& Thomson, 2000). While the results of this research cannot be generalized to all first-year university students, participants' voices support the transformative impact of transition programs when what is learned is put into practice.

\section{Research Findings}

Our research suggests that students who practiced what they learned in Foundations for Learning experienced enhanced academic competence. Eighteen 
students reported that they learned effective skills and good habits connected to better work and improved grades. They mentioned skills and habits associated with writing, study, academic integrity/referencing, time management, reflection, and exam preparation. Of enhanced academic competence, some students informed us that:

[The course] really helped organize my study habits, taught me how to stay on top of my assignments, which means I can hand in quality work rather than something I finished doing an hour before class.

I was quite sceptical when I first went to this class, but after I applied the skills I was learning and realized how effective they were, I found myself using them all the time. Learning basic skills like writing an effective thesis statement and organizing a compelling argument are truly essential to any undergraduate and I have used this basic knowledge in every paper I have written since.

As well as enhanced academic competence, our research also suggests that students who practiced what they learned in Foundations for Learning experienced enhanced academic confidence. Eleven students reported gaining academic confidence from the course content. Five mentioned feeling less fearful, panicked, out of place, less alone with struggles, or more "thoughtful of my studies and self." Six students felt more organized in school and life. Six students also noted a shift in their academic identity from high school to university. Students consistently mentioned that, when practiced within and outside Foundations for Learning, good habits "help." They decrease feelings of stress by increasing those of preparedness and "control" over academic and psychoemotional issues beyond the university.

Academically I found confidence in knowing that I wasn't the only one having a hard time. I learned to take each task step-bystep, and this way I got all my work com- pleted and on time because I know when and how to do it.

It helps to realize that a lot of people have the same "stupid" questions I did. It make me feel less out of place and more confident in my abilities to accomplish my academic goals.

It made me much more confident and more grown-up. I finally felt like a university student instead of a little kid who came out of high school.

Enhanced competence and confidence had two "ripple effects." First, after the Foundations for Learning course, students were more inclined to seek help - the number of students who accessed a teaching assistant increased from 12 to 27 and those who visited a professor increased from five to 18 . Second, Foundations for Learning students were inclined to take a mentorship role with peers, sharing what they learned. Twenty-six of the 35 respondents responded "yes" when asked if they've, "shared Foundations guidance?”

I have taught a few of my friends how to write a thesis statement, but perhaps the most useful (and seemingly obvious, but underused) skill was making a calendar every month for everything you need to do, just to put everything into perspective to maintain some sanity!

I was able to inform and direct my friends towards exam workshops and other extra help workshops.

I gave one of my friends some of my notes on good study habits [and] she found them very helpful.

\section{Conclusion}

Vincent Tinto $(1997,1994)$ has done extensive work 
on the student experience and on issues of persistence and retention as they relate to academic and social integration, and goal and institutional commitment. In a May 2007 presentation at Dalhousie University, "Promoting student success: Rethinking the 1st year of university study," Tinto recommended that firstyear seminars and/or bridging programs move into the curriculum mainstream as "embedded support." For example, a history course could include a mandatory tutorial on scholarly research and essay construction, while exam preparation strategies could be a psychology lecture module. Embedded support offers students a meaningful connection between the skills we expect and their application in the discipline. Like Tinto, we believe that long-term institutional support is important, via assorted and longterm help mechanisms. Some students may require embedded support throughout the undergraduate years. Some may profit from a first-year transition course and/or study skills workshop. Yet other students may benefit from a regular advising appointment, and/or an occasional visit to a writing centre, teaching assistant, or professor. No one persistence and retention strategy suits all students.

Our research suggests, however, that those students who decide to practice taught skills after a transition course such as Foundations for Learning are not just 'going through the motions,' acquiring credits to obtain a degree.

Made me want to do better once I realized how good I could do.

It helped me realize that I can do the work at a university level.

Rather, respondents' confidence that they can competently manage their academic success is an encouraging sign that they will be meaningfully satisfied and rewarded by their university experience.

\section{References}

Andrews, L., Andruske, C., \& Hawkey, C. (1996). Mapping the realities of first year post-secondary life: A study of students at three post-secondary institutions (Rep.). University of British Columbia, Vancouver, Centre for Policy Studies in Education.

Cook, C., Heath, F., \& Thompson, R. L. (2000). A meta-analysis of response rates in web- or internet-based surveys. Educational and Psychological Measurement, 60(6), 821-836.

Dommeyer, C. J., Baum, P., Hanna, R. W. \& Chapmen, K. S. (2004). Gathering faculty teaching evaluations by in-class and online surveys: Their effects on response rates and evaluations. Assessment and Evaluation in Higher Education, 29(5), 611-623.

Gardner, J. N. (2001). Focusing on the first-year student. Priorities, 17, 1-7.

Grayson, P. (1994). Comparative first-year experiences at York University: Science, arts, and Atkinson. Toronto, ON: York University Institute for Social Research.

Hyers, A. \& Nesest, M. (1998). The first-year seminar as a predictor of academic achievement and persistence. Journal of the First-Year Experience or Students in Transition, 10(1), 7-30.

Schnell, C., Louis, K.S., \& Doetkott, C. (2003). The first-year seminar as a means of improving college graduation rates. Journal of the First-Year Experience and Students in Transition, 15(1), 53-75.

Sherman, T. (1991). Creating a disposition to learn: Promoting enduring effects from learning improvement programs. Research and Teaching in Developmental Education, 8, 37-47.

Starke, M., Harth, M., \& Sirianni, F. (2001). Retention, bonding, and academic achievement: Success of a first-year seminar. Journal of the First-Year Experience or Students in Transition. 13(2), 7-35. 
Tinto, V. (1997). Classrooms as communities: Exploring the educational character of student persistence. The Journal of Higher Education, 68(6), 599-623.

Tinto, V. (1994). Leaving college: Rethinking the causes and cures of student attrition ( $2^{\text {nd }}$ ed.). Chicago: The University of Chicago Press. 